\title{
What Japanese Women with Breast Cancer Decide: A Mixed Methods Analysis of Web-Based Open-Ended Responses
}

\author{
Keiko Yamauchi ${ }^{1 *}$, Mitsuyo Nakashima², Motoyuki Nakao ${ }^{1}$
}

\begin{abstract}
Background: Living with breast cancer (BC) involves making many decisions, which immediately follow the diagnosis of BC. These decisions concern not only medical care, but also sociopsychological aspects, suggesting that women with $\mathrm{BC}$ need a wide range of support. To understand the challenges Japanese women encounter following a diagnosis of $\mathrm{BC}$, we holistically explored decisions women perceived themselves to have made following such a diagnosis. Methods: This was a cross-sectional, internet-based study comprising open-ended question. Qualitative content analysis was employed on the 1,158 free descriptive responses obtained from 549 participants. The frequencies of decisions were compared according to age at diagnosis using the chi-square test. Results: Approximately $80 \%$ of the participants reported having made some decisions. These decisions were separated into 14 categories: two categories were related to medical care and 12 were related to sociopsychological decisions. The frequency of sociopsychological decisions was higher than that of medical care decisions. About two-thirds of participants reported having made more than two decisions, and about one-third reported having made both medical and sociopsychological decisions. The decisions made by women varied based on age group at diagnosis. The lower the age group at diagnosis, the higher was the frequency of decisions related to both medical care and sociopsychological matters. Participants who were diagnosed with $\mathrm{BC}$ at a younger age were more likely to encounter a greater number of sociopsychological decisions, such as those concerning employment, fatality, and marriage, compared with those who were diagnosed at an older age. Conclusions: This analysis of open-ended questions suggests that Japanese women diagnosed with BC have a wide range of support needs that vary according to their age group at diagnosis.
\end{abstract}

Keywords: Breast cancer- medical care decisions- sociopsychological decisions

Asian Pac J Cancer Prev, 22 (9), 2909-2915

\section{Introduction}

Living with breast cancer (BC) involves making many decisions, which immediately follow the diagnosis of BC. These decisions concern not only medical matters, but also psychosocial ones, suggesting that women with BC need a wide range of support. Previous research investigating the impact of $\mathrm{BC}$ on Japanese women has focused on different aspects of a patient's life. For instance, almost $70 \%$ of adolescent and young adult BC survivors have been found to face issues related to reproductive function, with some giving up their hope of bearing a child despite wishing to have children (Furui et al., 2019). The positive and negative effects of informing their school-age children of their illness have also been articulated for both the women and their children, (Yoshida et al., 2010). About one-third of women tend to resign from their jobs on being diagnosed with BC (Saito et al., 2014). Moreover, the number of women with BC searching for information on $\mathrm{BC}$ on Japan's largest cancer information website in order to make medical decisions has been found to be higher than that of patients with any other type of cancer, and $22 \%$ of these women have searched for information about metastasis/recurrence (Okuhara et al., 2018). BC has been seen to affect body image and sexual function among the Japanese, especially among those who have undergone a total mastectomy (Adachi et al., 2007). Collectively, these researches suggest that decision-making or problemsolving related to $\mathrm{BC}$ diagnosis or $\mathrm{BC}$ treatment is a long and stressful process. Hence, it is likely that women diagnosed with $\mathrm{BC}$ are compelled to make more than one decision simultaneously. However, little attention has been paid to the decisions Japanese women have to make under these circumstances, or to the entirety of their experience after being diagnosed with $\mathrm{BC}$.

Accordingly, the purpose of this study was to holistically explore the decisions made by Japanese women. The findings of this study are expected to foster a better understanding of the challenges encountered by Japanese women when they are diagnosed with BC. 


\section{Materials and Methods}

\section{Respondents and data collection}

We conducted an anonymous, cross-sectional internet survey with a convenience sample of Japanese female BC survivors who were registered with an online marketing research company (Rakuten Insight Inc. Osaka, Japan). The eligibility criteria were: (1) being diagnosed with BC, (2) having had primary treatment for BC including surgery in Japan, and (3) being older than 20 years of age at the time of taking the survey. Women who self-reported a history of $\mathrm{BC}$ to the company were invited to participate in this survey by email between February 15 and 18, 2019.

A total of 550 women completed the online survey. We excluded one questionnaire as it contained an incomplete sentence in the open-ended question section. Thus, we analyzed 1,158 free descriptive responses from 549 participants.

\section{Measurements}

The self-administered survey consisted of multiplechoice and open-ended questions. The multiplechoice questions sought to obtain information on the sociodemographic characteristics of age, marital status, household income, employment status, youngest child at diagnosis and education; and the cancer-related characteristics of $\mathrm{BC}$ stage, type of $\mathrm{BC}$ treatment including surgery, and presence/absence of $\mathrm{BC}$ recurrence and metastasis. The open-ended question asked from the participants was: "From the time you were diagnosed with breast cancer to the present, please list at the most three things that you have decided because you got sick and that have remained in your mind, regardless of whether or not they were directly related to treatment."

\section{Qualitative content analysis}

All responses were grouped by content based on the co-occurrence of frequently appearing words using $\mathrm{KH}$ Coder version 3 (Higuchi, 2016; Higuchi, 2017). After this computerized coding, we categorized the groups containing the responses "nothing in particular" and "I do not remember" as "no decision." Further, we named the group containing the verbs "regret," "fear," and "worry" as "thought," and separated it from the "decision" category. Nouns reflecting a situation beyond the patient's control, such as "recurrences," "metastasis," or "prognoses" were categorized into "mindset" if these words were concomitant with "changed lifestyle" or "be careful." Two of the researchers (KY and M Nakashima) discussed all coding process and finally identified 14 categories and nine subcategories of decisions made by Japanese women after being diagnosed with $\mathrm{BC}$.

\section{Statistical analysis}

The chi-square and Fisher's exact test were used for analysis. Majorly, two comparison were made: the differences in the characteristics of the participants were compared by the presence or absence of decisions/ thoughts, snd the frequencies of decisions in each category were compared by age group at diagnosis. Statistical significance was set at $\mathrm{p}<.05$. The analyses were conducted using SPSS version 24 (IBM Corporation, Armonk, NY, USA).

\section{Results}

\section{Characteristics of the participants}

The sociodemographic and cancer-related characteristics of the participants are shown in Table 1 by the presence or absence of decisions/thoughts. Of the 549 study participants, $78(14.0 \%)$ did not report any decision or thought since being diagnosed with BC. Compared to their counterparts, participants who were highly educated or had higher household income at diagnosis were more likely to recognize that they had made some decisions or had thoughts since being diagnosed with BC. Women who did not remember their cancer stage at diagnosis and women who received radiation therapy were more likely to have not made any decisions.

\section{Content of the decisions}

We extracted two core categories of decisions made by Japanese women after being diagnosed with BC (Table 2 and the detail is found in the Supplementary Table $1)$ : those regarding medical care and those regarding sociopsychological matters. The core category of medical care was subdivided into the following two categories: "BC treatment," and "Medical care other than treatment." Further, while "BC treatment" contained the subcategories of "Surgery" and "Chemotherapy," "Medical care other than treatment" contained the subcategories of "Selection of a hospital or physician," "Obtaining a second opinion," and "Trusting doctor." About half of the participants $(47.0 \%)$ reported making decisions in the medical care category. Selection of the surgical procedure, including whether to undergo reconstructive surgery, was the most frequently reported decision concerning $\mathrm{BC}$ treatment $(23.3 \%)$, followed by decisions regarding chemotherapy (8.7\%). Participants faced decisions not only on whether to receive chemotherapy but also on whether to continue or terminate chemotherapy during treatment.

The core category of sociopsychological matters comprised the following 12 categories: "Mindset," "Family matters," "Employment," "Financial matters," "Lifestyle modification," "Informing others about BC," "Pregnancy/childbirth," "Preparing for one's death", "Appearance," "Obtaining information," "Marriage/ divorce," and "Seeking help." Nearly two-third of participants $(65.6 \%)$ made some sociopsychological decisions. The most frequent $(27.5 \%)$ sociopsychological decision related to determining a new mindset, such as one's attitude toward life with $\mathrm{BC}$ and $\mathrm{BC}$ treatment, hoping for positivity in life, and planning for the future. In family matters $(24.4 \%)$, about half of the decisions reported were related to children. Decisions regarding employment concerned both the continuation and discontinuation of employment (23.7\%). Decisions regarding financial matters concerned both medical and living expenses $(14.4 \%)$. Some participants decided to change their lifestyle, such as by improving their eating and exercise habits, giving up smoking, incorporating self-care, or living environmentally (7.7\%). Participants 
Table 1. Characteristics of Participants by Presence or Absence of Decisions/Thoughts ( $\mathrm{n}=549)$

\begin{tabular}{|c|c|c|c|c|}
\hline & \multirow{2}{*}{$\begin{array}{l}\text { Total } \\
(\mathrm{n}, \%)\end{array}$} & \multicolumn{2}{|c|}{ Decisions/ Thoughts (n, \%) } & \multirow[t]{2}{*}{ p-value } \\
\hline & & None & Some & \\
\hline \multicolumn{5}{|l|}{ Age at diagnosis } \\
\hline$\leq 39$ & $101(18.4)$ & $11(14.1)$ & $90(19.1)$ & \multirow[t]{3}{*}{0.522} \\
\hline $40-49$ & $257(46.8)$ & $40(51.3)$ & $217(46.1)$ & \\
\hline$\geq 50$ & $191(34.8)$ & $27(34.6)$ & $164(34.8)$ & \\
\hline \multicolumn{5}{|l|}{ Marital status at diagnosis } \\
\hline Single & $133(24.2)$ & $19(24.4)$ & $114(24.2)$ & \multirow[t]{3}{*}{0.964} \\
\hline Married & $391(71.2)$ & $55(70.5)$ & $336(71.3)$ & \\
\hline Other & $25(4.6)$ & $4(5.1)$ & $21(4.5)$ & \\
\hline \multicolumn{5}{|l|}{ Education } \\
\hline$\leq$ High school & $169(30.8)$ & $33(42.3)$ & $136(28.9)$ & \multirow[t]{2}{*}{0.017} \\
\hline$>$ High school & $380(69.2)$ & $45(57.7)$ & $335(71.1)$ & \\
\hline \multicolumn{5}{|l|}{ Household income at diagnosis } \\
\hline$<¥ 5,000.000$ & $276(50.3)$ & $50(64.1)$ & $226(48.0)$ & \multirow[t]{2}{*}{0.008} \\
\hline$\geq ¥ 5,000.000$ & $273(49.7)$ & $28(35.9)$ & $245(52.0)$ & \\
\hline \multicolumn{5}{|l|}{ Employment status at diagnosis } \\
\hline Regular employment & $138(25.1)$ & $11(14.1)$ & $127(27.0)$ & \multirow[t]{4}{*}{0.093} \\
\hline Non-regular employment & $179(32.6)$ & $30(38.5)$ & $149(31.6)$ & \\
\hline Housewife & $165(30.1)$ & $28(35.9)$ & $137(29.1)$ & \\
\hline Other & $67(12.2)$ & $9(11.5)$ & $58(12.3)$ & \\
\hline \multicolumn{5}{|l|}{ Child at diagnosis } \\
\hline No child & $215(39.2)$ & $40(51.3)$ & $175(37.2)$ & \multirow[t]{2}{*}{0.113} \\
\hline With a child (or children) & $334(60.8)$ & $38(48.7)$ & $296(62.8)$ & \\
\hline \multicolumn{5}{|l|}{ Family history of breast cancer } \\
\hline No & $410(74.7)$ & $61(78.2)$ & $349(74.1)$ & \multirow[t]{2}{*}{0.440} \\
\hline Yes & $139(25.3)$ & $17(21.8)$ & $122(25.9)$ & \\
\hline \multicolumn{5}{|l|}{ BC stage } \\
\hline 0 & $81(14.8)$ & $7(9.0)$ & $74(15.7)$ & \multirow[t]{5}{*}{0.003} \\
\hline I & $195(35.5)$ & $31(39.7)$ & $164(34.8)$ & \\
\hline II & $139(25.3)$ & $14(17.9)$ & $125(26.5)$ & \\
\hline$\geq$ III & $62(11.3)$ & $6(7.7)$ & $56(11.9)$ & \\
\hline Other (do not remember, etc.) & $72(13.1)$ & $20(25.6)$ & $52(11.0)$ & \\
\hline \multicolumn{5}{|l|}{ Surgery } \\
\hline Total Mastectomy & $230(41.9)$ & $28(35.9)$ & $202(42.9)$ & \multirow[t]{3}{*}{0.121} \\
\hline Breast Conserving Surgery & $277(50.5)$ & $47(60.3)$ & $230(48.8)$ & \\
\hline Other & $42(7.7)$ & $3(3.8)$ & $39(8.3)$ & \\
\hline \multicolumn{5}{|l|}{ Recurrence/metastasis of $\mathrm{BC}$} \\
\hline No & $471(85.8)$ & $70(89.7)$ & $401(85.1)$ & 0.281 \\
\hline Yes & $78(14.2)$ & $8(10.3)$ & $70(14.9)$ & \\
\hline Radiation therapy & & & & \\
\hline No & $233(42.4)$ & $24(30.8)$ & $209(44.4)$ & 0.016 \\
\hline Yes & $316(57.6)$ & $54(69.2)$ & $262(55.6)$ & \\
\hline Chemotherapy & & & & \\
\hline No & $319(58.1)$ & $51(65.4)$ & $268(56.9)$ & 0.160 \\
\hline Yes & $230(41.9)$ & $27(34.6)$ & $203(43.1)$ & \\
\hline Hormone therapy & & & & \\
\hline No & $157(28.6)$ & $21(26.9)$ & $136(28.9)$ & 0.724 \\
\hline Yes & $392(71.4)$ & $57(73.1)$ & $335(71.1)$ & \\
\hline
\end{tabular}


Table 2. Decisions and Their Frequencies Made by Women with BC Following Diagnosis and by Age Group at Diagnosis $(n=549)$

\begin{tabular}{lccccc}
\hline & Total & \multicolumn{2}{c}{ Age groups at diagnosis (n, \%) } & p-value \\
\hline Categories of decisions & $(\mathrm{n}, \%)$ & $\leq 39$ & $40-49$ & $\geq 50$ & \\
I. Decisions regarding medical care & $258(47.0)$ & $51(50.5)$ & $122(47.5)$ & $85(44.5)$ & 0.608 \\
1. BC treatments & $209(38.1)$ & $45(44.6)$ & $99(38.5)$ & $65(34.0)$ & 0.208 \\
2. Medical care other than treatments & $90(16.4)$ & $12(11.9)$ & $43(16.7)$ & $35(18.3)$ & 0.360 \\
II. Decisions regarding sociopsychological matters & $360(65.6)$ & $78(77.2)$ & $168(65.4)$ & $114(59.7)$ & 0.011 \\
3. Mindset & $151(27.5)$ & $25(24.8)$ & $57(22.2)$ & $46(24.1)$ & 0.833 \\
4. Family matters & $134(24.4)$ & $32(31.7)$ & $58(22.6)$ & $44(23.0)$ & 0.168 \\
5. Employment & $130(23.7)$ & $34(33.7)$ & $60(23.3)$ & $36(18.8)$ & 0.018 \\
6. Financial matters & $79(14.4)$ & $19(18.8)$ & $38(14.8)$ & $22(11.5)$ & 0.233 \\
7. Lifestyle modification & $42(7.7)$ & $12(11.9)$ & $15(5.8)$ & $15(7.9)$ & 0.152 \\
8. Informing others about BC & $32(5.8)$ & $6(5.9)$ & $12(4.7)$ & $14(7.3)$ & 0.493 \\
9. Pregnancy/childbirth & $13(2.4)$ & $8(7.9)$ & $5(1.9)$ & $0(0.0)$ & $<0.001$ \\
10. Preparing for one's death & $19(3.5)$ & $2(2.0)$ & $9(3.5)$ & $8(4.2)$ & 0.617 \\
11. Appearance & $12(2.2)$ & $3(3.0)$ & $8(3.1)$ & $1(0.5)$ & 0.150 \\
12. Obtaining information & $9(1.6)$ & $0(0.0)$ & $5(1.9)$ & $4(2.1)$ & 0.354 \\
13. Marriage/divorce & $7(1.3)$ & $4(4.0)$ & $3(1.2)$ & $0(0.0)$ & 0.016 \\
14. Seeking help & $5(0.9)$ & $1(1.0)$ & $3(1.2)$ & $0(0.0)$ & 0.524 \\
\hline
\end{tabular}

reported making decisions relating to whom they should inform about their disease (including family members), and when they should provide this information $(5.8 \%)$. Younger survivors often faced decisions regarding pregnancy/childbirth, such as whether to opt for fertility preservation or infertility treatment, or whether to have a child in the future $(2.4 \%)$. Some women made decisions regarding their attitudes toward their death and putting their house in order $(3.5 \%)$. Decisions regarding appearance included not only working on looking as they did before surgery, but also on dressing up more than they did before their diagnosis $(2.2 \%)$. Nine participants decided to obtain information regarding $\mathrm{BC}$ and $\mathrm{BC}$ treatment or information on making their will and tackling the question of inheritance $(1.6 \%)$. Seven participants decided to start or end a marriage (1.3\%). Five participants decided to ask someone for help in overcoming the difficulties caused by $\mathrm{BC}$ and $\mathrm{BC}$ treatment, or for encouragement in continuing treatment for $\mathrm{BC}(0.9 \%)$. A few women also reported thoughts of fear, worry, and regret following a BC diagnosis (Supplementary Table 2).

Table 3 presents the frequencies of the core categories of the decisions by number of responses. Of the 549 study participants, $443(80.7 \%)$ reported making some decisions, 348 (63.4\%) reported making more than two decisions, and 175 (31.9\%) reported making both medical and sociopsychological decisions since being diagnosed with BC.

\section{Influence of age on decisions}

Table 2 shows the influence of age at diagnosis on the content of decisions. Overall, lower the age group at diagnosis, the higher was the frequency of decisions relating to both medical care and sociopsychological matters. Statistical differences between age groups were observed in sociopsychological decisions overall, and specifically in decisions regarding employment, pregnancy/childbirth, and marriage/divorce. Participants who were diagnosed with $\mathrm{BC}$ at a younger age were more likely to encounter a greater number of sociopsychological decisions, such as those concerning employment, fatality, and marriage, compared with those who were diagnosed at an older age. A similar trend was observed in the frequency of decisions regarding the selection of $\mathrm{BC}$ treatment and financial matters. In contrast, the higher the age group at diagnosis, the higher was the frequency of decisions regarding medical care other than surgery.

Table 3. Categories of Responses and Their Frequencies $(n=549)$

\begin{tabular}{|c|c|c|c|}
\hline & \multicolumn{3}{|c|}{ Number of decisions made (frequency of responses) } \\
\hline & $1(\mathrm{n}=118)$ & $2(\mathrm{n}=100)$ & $3(n=253)$ \\
\hline \multirow{3}{*}{ 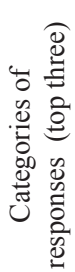 } & $\begin{array}{c}\text { Decisions regarding sociopsychological } \\
\text { matters }(\mathrm{n}=57,48.3 \%)\end{array}$ & $\begin{array}{c}\text { Decisions regarding medical care }+ \\
\text { Decisions regarding sociopsychological } \\
\text { matters }(n=44,44.0 \%)\end{array}$ & $\begin{array}{c}\text { Decisions regarding medical care }+ \\
\text { Decisions regarding sociopsychological } \\
\text { matters }(\mathrm{n}=123,48.6 \%)\end{array}$ \\
\hline & $\begin{array}{l}\text { Decisions regarding medical care } \\
\qquad(\mathrm{n}=38,32.2 \%)\end{array}$ & $\begin{array}{l}\text { Decisions regarding sociopsychological } \\
\text { matters }(n=32,32.0 \%)\end{array}$ & $\begin{array}{c}\text { Decisions regarding sociopsychological } \\
\text { matters }(n=70,27.7 \%)\end{array}$ \\
\hline & $\begin{array}{l}\text { Thoughts following BC diagnosis } \\
\qquad(\mathrm{n}=20,16.9 \%)\end{array}$ & $\begin{array}{l}\text { Decisions regarding medical care } \\
\qquad(\mathrm{n}=11,11.0 \%)\end{array}$ & $\begin{array}{l}\text { Decisions regarding medical care } \\
\qquad(\mathrm{n}=23,9.1 \%)\end{array}$ \\
\hline
\end{tabular}




\section{Discussion}

With the purpose of comprehensively understanding the challenges Japanese women encounter following a diagnosis of $\mathrm{BC}$, we explored the responses of Japanese women with $\mathrm{BC}$ to an open-ended questionnaire about decisions they made since being diagnosed with $\mathrm{BC}$. More than $80 \%$ of the participants reported that they had made some decisions. Qualitative coding methods identified 14 categories of decisions: two related to medical care and 12 related to sociopsychological decisions. About one-third of participants reported making both medical and sociopsychological decisions. Women's decisions varied according to their age group at diagnosis. Younger women were more likely to make a greater number of sociopsychological decisions, especially decisions concerning employment, financial matters, fertility, and marriage.

Decision-making that is not directly related to $\mathrm{BC}$ treatment may be significant for patients. The current study shows that more than $80 \%$ of participants reported making some decisions since being diagnosed with BC; $47 \%$ decided about medical care, of which $38 \%$ reported making decisions about BC treatment. Between 70\% and $80 \%$ of Japanese $\mathrm{BC}$ patients have been found to decide BC treatment alone or collaboratively with doctors (Nakashima et al., 2012; Shimizu et al., 2019; Yamauchi et al., 2019). In this regard, considering that a patient playing an active or collaborative role in decision-making for treatment has made the decision themselves, fewer women reported decision-making regarding treatment in our study compared with the results reported in previous studies. The open-ended question we used in this study may have led to this difference between the results of the current and previous studies. We asked the study participants to list the decisions that have remained in their minds, suggesting that selecting BC treatment may not have been a significant event for the patients, or that they may have faced more difficult decisions than those regarding $\mathrm{BC}$ treatment. However, $66 \%$ of participants in this study reported making decisions regarding sociopsychological matters, suggesting that the influence of sociopsychological decisions is felt long after the completion of primary treatment. The other possibility is that some participants may not have recognized that they had participated in choosing their BC treatments, as approximately $26-43 \%$ of these decisions have been found to be conducted collaboratively with doctors (Nakashima et al., 2012; Shimizu et al., 2019; Yamauchi et al., 2019). There is a positive association between involvement in treatment decision-making and quality of life (QOL) in cancer patients (Hack et al., 2006; Andersen et al., 2009; Atherton et al., 2013; Andersen et al., 2018), suggesting that the manner in which these psychosocial decisions are made, along with the decisions themselves, contribute to increasing a patients' QOL. Even though sociopsychological status after primary care significantly influences cancer patients' QOL (Kobayashi et al., 2008; Konieczny et al., 2020), to the best of our knowledge, no research has been conducted on how patients' involvement in sociopsychological decision-making or how the type of sociopsychological made by them affect their QOL afterward. Further studies are needed to investigate how sociopsychological decisions impact patients and their lives longitudinally.

Open-ended questions such as those used in the current study could elicit more holistic responses on what women do and need after being diagnosed with $\mathrm{BC}$, especially with regard to sociopsychological decisions. In this study, decisions related to employment, finance, and family matters were the frequently reported sociopsychological decisions, while decisions related to fertility and marriage were characteristic of younger participants. These items have been articulated as sociopsychological challenges, and factors associated with them have been investigated in order to develop better assistance in the lives of Japanese BC survivors (Yamaguchi et al., 2007; Takahashi et al., 2008; Yoshida et al., 2010; Saito et al., 2014; Umezawa et al., 2015; Hisamura et al., 2018; Takahashi et al., 2018; Takeuchi et al., 2018; Furui et al., 2019). Additionally, our study found that determining a new mindset accounted as a frequently made decision across all age groups. In this regard, planning for the future is one of the biggest problems experienced by Japanese cancer survivors (Hisamura et al., 2018; Takeuchi et al., 2018). Preparing mentally for life during and after BC treatment may make life easier for $\mathrm{BC}$ survivors. This requires an investigation into determining patients' mindset, despite the variable being less emphasized among cancer-related difficulties.

Patients' needs may differ by situation and may be wide-ranging. Our study reveals that about two-third of participants made more than two decisions on matters both related and unrelated to medical care. Yamaguchi et al. extracted 16 categories of decisions, including matters both related and unrelated to medical care, based on the distress and inquiries of 48,031 pooled cases of Japanese cancer patients from a questionnaire survey and consultation service (Yamaguchi et al., 2007). In their study, the frequency of decisions regarding sociopsychological matters differed considerably depending on the method of data collection. The results from their questionnaire survey corroborate with the results of our study: the frequency of decisions regarding sociopsychological matters was higher than the frequency of decisions regarding medical care in both cases; however, the results from the consultation service at the hospital showed the opposite trend. This suggests that patients' needs differ between clinical and non-clinical settings. Furthermore, many participants in our study reported making more than two decisions about medical care or medical care combined with sociopsychological matters. This suggests that collaboration between professionals' support and non-medical support, such as that offered by peers and workplaces, is needed to comprehensively help women with BC (Umezawa et al., 2015; Takahashi et al., 2018).

The support needed for BC patients depends on their age at diagnosis. Our study revealed that the lower the age group at diagnosis, the higher was the frequency of sociopsychological decisions. Age differences were observed in the categories of sociopsychological decisions: younger participants decided how to take care of, and whom to ask for help while taking care of 
children during hospitalization and treatment, while older participants were more likely to do so for a husband or elderly parents. Decisions relating pregnancy/childbirth and marriage/divorce were made only by participants who were younger than 49 years of age. Patients in this age group considered the influence on pregnancy/childbirth and their sex life when they chose their cancer treatment (Yamauchi et al., 2019). This shows that measures for providing support that match the age or life stage of the patients need to be developed.

This study had several limitations. First, our findings are likely to be limited in generalizability because of selection bias due to the nature of internet-based, selfadministered surveys. Second, $14 \%$ of the participants did not recall or report making any decisions. This may be because of the length of time that had passed since they were diagnosed with $\mathrm{BC}$, suggesting a recall bias, and the rare practice of autonomous decision-making amongst Japanese at the time of their diagnosis. Third, even though we asked participants what kind of decisions they made, $12 \%$ of them expressed their thoughts of fear, worry, and regret. The questions might remind them, more strongly than they had anticipated, of their feelings when they made some decision or thoughts brought about by the consequence of those decisions. As such, these responses provided by them might be linked to the decisions made by them, but we separated these responses from the decision category. Hence, we might have missed extracting some decisions from the participants' responses.

Despite these limitations, this study highlights that when Japanese women are diagnosed with BC, they make a wide range of decisions that include both medical care and sociopsychological matters. These decisions vary according to their age at the time of diagnosis. Comprehensively looking at the needs of women diagnosed with $\mathrm{BC}$ will provide information to physicians and other medical specialists about medical and social support. This information will also help women who are newly diagnosed with $\mathrm{BC}$ in preparing for the challenges they might encounter.

\section{Author Contribution Statement}

KY participated in the study design, coordination of data collection, analysis and interpretation of the data, and drafting the manuscript. M Nakashima participated in the study design, data analysis and interpretation of the data. N Nakao participated in drafting the manuscript and proofreading the final submission. All authors reviewed the results and approved the final version of the manuscript.

\section{Acknowledgements}

None.

\section{Ethics approval and consent to participate}

This study was approved by the Clinical Ethical Review Board of Kurume University's, School of Medicine (Approval number: 13138). Prior to the investigation, participants were provided with explanations via the Internet regarding the purpose and method of the study; they were also given information regarding the handling of the results. The study was conducted upon receiving the participants' signed consent online.

\section{Consent for publication \\ Not applicable}

\section{Availability of data and material}

Datasets used and analyzed during the currents study are available from the corresponding author on reasonable request.

\section{Funding Statement}

This study was supported in part by a Grant-in-Aid for Challenging Exploratory Research (Grant No.'s 25670254 and 16K15313) from the Japan Society for the Promotion of Science. The funding body had no role in the design of the study; collection, analysis, and interpretation of data; or in the writing of the manuscript.

\section{References}

Adachi K, Ueno T, Fujioka T, Fujitomi Y, Ueo H (2007). Psychosocial factors affecting the therapeutic decisionmaking and postoperative mood states in Japanese breast cancer patients who underwent various types of surgery: body image and sexuality. Jpn J Clin Oncol, 37, 412-8.

Andersen MR, Bowen DJ, Morea J, Stein KD, Baker F (2009). Involvement in decision-making and breast cancer survivor quality of life. Health Psychol, 28, 29-37.

Andersen MR, Sweet E, Hager S, et al (2018). Use of integrative oncology, involvement in decision-making, and breast cancer survivor health-related quality of life in the first 5 years postdiagnosis. Integr Cancer Ther, 17, 636-45.

Atherton PJ, Smith T, Singh JA, et al (2013). The relation between cancer patient treatment decision-making roles and quality of life. Cancer, 119, 2342-9.

Furui T, Takai Y, Kimura F, et al (2019). Fertility preservation in adolescent and young adult cancer patients: From a part of a national survey on oncofertility in Japan. Reprod Med Biol, 18, 97-104.

Hack TF, Degner LF, Watson P, Sinha L (2006). Do patients benefit from participating in medical decision making? Longitudinal follow-up of women with breast cancer. Psychooncology, 15, 9-19.

Higuchi K (2016). A two-step approach to quantitative content analysis: KH Coder tutorial using Anne of Green Gables (Part I). Ritsumeikan Soc Sci Rev, 52, 77-91.

Higuchi K (2017). A two-step approach to quantitative content analysis: KH Coder tutorial using Anne of Green Gables (Part II). Ritsumeikan Soc Sci Rev, 53, 137-47.

Hisamura K, Matsushima E, Tsukayama S, Murakami H, Motoo Y (2018). An exploratory study of social problems experienced by ambulatory cancer patients in Japan: Frequency and association with perceived need for help. Psychooncology, 27, 1704-10.

Kobayashi K, Morita S, Shimonagayoshi M, et al (2008). Effects of socioeconomic factors and cancer survivors' worries on their quality of life (QOL) in Japan. Psychooncology, 17, 606-11.

Konieczny M, Cipora E, Sygit K, Fal A (2020). Quality of life of women with breast cancer and socio-demographic factors. 
Asian Pac J Cancer Prev, 21, 185-93.

Nakashima M, Kuroki S, Shinkoda H, et al (2012). Informationseeking experiences and decision-making roles of Japanese women with breast cancer. Fukuoka Igaku Zasshi, 103, 120-30.

Okuhara T, Ishikawa H, Urakubo A, et al (2018). Cancer information needs according to cancer type: A content analysis of data from Japan's largest cancer information website. Prev Med Rep, 12, 245-52.

Saito N, Takahashi M, Sairenchi T, Muto T (2014). The impact of breast cancer on employment among Japanese women. J Occup Health, 56, 49-55.

Shimizu C, Sakata Y, Sakai R, et al (2019). Pharmacotherapy decision-making among patients with breast cancer in Japan: results of an online survey. Breast Cancer, 26, 799-807.

Takahashi M, Ohno S, Inoue H, et al (2008). Impact of breast cancer diagnosis and treatment on women's sexuality: a survey of Japanese patients. Psychooncology, 17, 901-7.

Takahashi M, Tsuchiya M, Horio Y, et al (2018). Job resignation after cancer diagnosis among working survivors in Japan: timing, reasons and change of information needs over time. Jpn J Clin Oncol, 48, 43-51.

Takeuchi T, Ichikura K, Amano K, Takeshita W, Hisamura K (2018). The degree of social difficulties experienced by cancer patients and their spouses. BMC Palliat Care, 17, 83.

Umezawa S, Fujisawa D, Fujimori M, et al (2015). Prevalence, associated factors and source of support concerning supportive care needs among Japanese cancer survivors. Psychooncology, 24, 635-42.

Yamaguchi K, Ishikawa M, Takada Y, et al (2007). Cancer patients' distresses and inquiries: proposal of four-level classification based on consultation service and questionnaire survey. Cancer Sci, 98, 612-6.

Yamauchi K, Nakao M, Nakashima M (2019). Correlates of regret with treatment decision-making among Japanese women with breast cancer: results of an internet-based crosssectional survey. BMC Womens Health, 19, 86.

Yoshida S, Otani H, Hirai K, et al (2010). A qualitative study of decision-making by breast cancer patients about telling their children about their illness. Support Care Cancer, 18, 439-47.

This work is licensed under a Creative Commons AttributionNon Commercial 4.0 International License. 